\title{
DESIGN AND OPTIMIZATION OF PINTLE INJECTOR FOR LIQUID ROCKET ENGINE
}

\author{
Dr. R Rajendran, Professor \\ Department of Aeronautical Engineering, \\ Dayananda Sagar College of Engineering, Bangalore, Karnataka, India \\ Samiksha Prasad, Subhashree S, Toshith S Phutane, Vedanth S Saoor \\ Students, Department of Aeronautical Engineering, \\ Dayananda Sagar College of Engineering, Bangalore, Karnataka, India
}

\begin{abstract}
A pintle injector is a variable-area injector that can control the mass flow rate of the fuel and oxidizer used, subsequently discarding an enormous injector plate having a few injector components with a solitary injector unit. Throttling performance requires the fulfilment of two major parameters i.e. the spray angle and SMD. To achieve a good reasonable result for the above two parameters, there are two other regulatory parameters which govern them i.e TMR and Weber Number. Both these parameters are non-dimensional in nature and suggest some main behavioural criteria. The study will be bound to these parameters and on how they alter the performance of pintle injector. Initially theoretical study on various parameters are performed. To enhance the observation further, theoretical calculations are performed and analysis is done to obtain parameters after pressure losses are considered due to the geometric constraints with involvement of other conditions, to get the values almost close to a real valued flow. The analysis is also performed to study the recirculation and the parameters which are directly involved in generating this phenomenon.
\end{abstract}

Keywords - Throttling, Combustion instability, pintle injector, TMR, spray angle, SMD.

\section{INTRODUCTION}

Interplanetary missions are a part of all growing space organizations around the globe. Space missions are always filled with a huge amount of challenges. One such challenging situation is the dynamic thrust variation of the rocket motors to stay on its own trajectory. The throttling effect rises to a very devastating phenomenon called combustion instability. This phenomenon can blow up the entire vehicle in a very short span of time. Thus, making it to the mandatory issue list which has to be dealt with very success in the project and the mission. Tracing back to the reason for its occurrence we come across a term called as the pressure drop. This is one the main reasons argued to initiate combustion instability. The suggestion is that the pressure drop has to be high enough to prevent onset of any type of combustion instability. Pintle injector was developed in 1950 by the TRW predecessors of the Northrop Grumman for application in the liquid propellant rocket engine which served the main purpose in the Apollo Missions Lunar Module. This actually began as an experiment at JPL to measure the mixing and combustion time of the hypergolic propellants in the mid of the 1950's. But the actual patent of the pintle injector came out in the year of 1972. Some of the previous missions in which this sort of injectors was used were Apollo LMDE, Delta launch vehicle, NASA Chandra etc. The SpaceX company which is well established in the space exploration domain used the pintle injector for their Merlin and Grasshopper engines and also stated that these will be the most favourable kind of injectors that will be used by majority agencies for their application in the near future.

\section{CONCEPT FOR PINTLE INJECTOR}

\section{A. Throttling -}

Certain missions require variation in the thrust to either decelerate or change the attitude of the vehicle. In such a case the vehicle should be adequately built to safely vary its thrust according to the requirement of the mission. Throttling has a brutal impact on the performance of the vehicle and hence it becomes mandatory to design the mechanism i.e., the injectors which handle the throttling at utmost care. There are two ways to control the thrust : through variation in the mass flow rate or variation of the thrust duration. Through variation in the mass flow rates, the pressure drop decreases and hence the performance is reduced. The liquid pressure drop changes with the square of mass flow rate while the flow in the combustion chamber is linear. A small glitch that arises is if the injector is made to work for prolonged time at a very low throttling range, there are chances of instability even with a pintle injector application.

\section{B. Combustion instability -}

When there is a regenerative feedback between the combustion phenomenon and energy released there is onset of high oscillation in the combustion chamber which is further transmitted through the engine and the high oscillating 


\section{International Journal of Engineering Applied Sciences and Technology, 2020 \\ Vol. 5, Issue 1, ISSN No. 2455-2143, Pages 151-159 \\ Published Online May 2020 in IJEAST (http://www.ijeast.com)}

frequency is absorbed by the complete structure of the rocket. The energy release is insufficient at the antinodes for the entire range of acoustic modes. Just before this happens the engine undergoes chugging. Chugging is mainly caused due to the immediate variations in the mass flow rates of the propellants as a result of the changes in the pressure drop across the injector. The other reason is due to the droplets which are retained back from undergoing combustion. They experience very high relative winds of the combustion gases which triggers the flow and high frequency modes are generated internally through the combustion chamber. This is further transmitted to the injector and since the turbomachines are stalled quickly during such times, they initiate combustion instability. This is the reason why recirculation is believed to be one of the saviours in the prevention of combustion instability. The other reason is due to the highly varying acoustic speeds inside the chamber. This may be initiated due to the continual change in the properties of the propellant. This is the reason why it is necessary to maintain certain critical parameters like $\mathrm{O} / \mathrm{F}$, $\mathrm{cp} / \mathrm{cv}$ etc. constant even while performing throttling. The acoustic waves should be damped. This has been satisfied by the use of certain devices like acoustic cavity, baffles, spooks etc. This additional arrangement is almost eliminated by the use of the pintle injectors.

\section{Basic definitions -}

Sauter mean diameter (SMD): In fluid dynamics, Sauter mean diameter is an average of particle size. It is defined as the diameter of a sphere that has the same volume or surface area ratio as a particle of interest. SMD are highly impacted by the weber number, pintle angle and Lopen. The weber number has to be maintained high to procure a very fine spray. The relative velocities for such SMD's are meant to be as high as possible since they play a vital role and are directly proportional to the SMD's.

Spray angle: It is the angle formed by the cone of the liquid leaving a nozzle orifice. The spray angle is expected to stay steady all through the whole spray distance. Spray angles are directly influenced by the TMR's. As per the observations, a higher spray angle generates a uniform combustion field where every antinode is being sufficed with enough energy. Hence the possibility of combustion instability is less.

Total Momentum Ratios: TMR is the ratio between the momentum of the oxidizer to that of the sum of the momentum of the propellants. For a rocket depending on the mission and resource requirements, it is classified as an oxy-rich engine or fuel-rich engine. The simple fact of the ratio between the momentums gives a brief idea on how the flow regimes are formed further downstream. As mentioned earlier a uniform and stable spray angles are required and since this parameter is a major indicator and influencer on the spray angles, makes it to be valued more during the designing of the injectors.

\section{PINTLE INJECTOR}

Pintle injector is a variable area injector which is beneficial during the throttling to maintain adequate pressure loss and prevent any trigger in the combustion stability of the engine which might be proven to be fatal. Pintle type injectors are termed to be the future of the injectors in the liquid propulsion division under aerospace industry. They have relatively easier design compared to other injector types and are cheaper for manufacturing as well. Optimized injection levels are expected at all injection levels. This can be achieved by using variable area injectors. The use of fixed area injectors proves to be a haphazard at lower thrust levels or at lower mass flow of the propellants. Moreover, the pintle injector covers a wider range of spray angle and hence the complexity of numerous impinging elements spreader through the faceplate is skipped. There is a presence of an inherent recirculation zone due to which we obtain a very high performance. The propellant in fumed state is recirculated till the entire propellant undergoes combustion

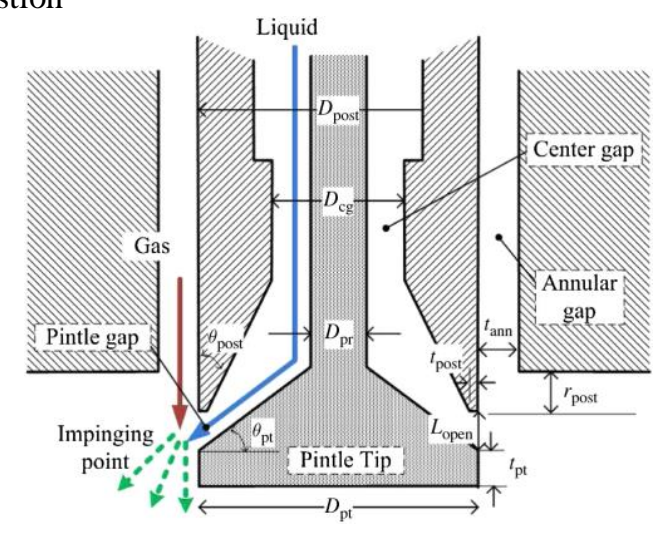

Fig. 1. Schematic respresntation of pintle injector

The pintle injector mainly has a pintle rod, a fuel sleeve, an oxidiser sleeve and a pintle head. In addition to this other secondary parts include the inlets to the respective chambers and a face plate for uniform distribution of the fuel as shown in the above figure. A pintle injector is a variable area injector consisting of two concentric tubes ( also known as sleeve in 2D diagram ) and a central pintle rod inside the concentric tubes. The oxidiser is conventionally allowed to flow inside the outer concentric tube coming out as a stream while the fuel is made to flow inside the inner concentric tube in a straight line. Once the propellants ( fuel and oxidiser ) reach the end point of the injector they intersect or impinge to form a mixture with a specific mixture ratio required for a particular mission application. Throttling is achieved by either moving the inner pintle or the outer sleeve. 


\section{International Journal of Engineering Applied Sciences and Technology, 2020 \\ Vol. 5, Issue 1, ISSN No. 2455-2143, Pages 151-159 \\ Published Online May 2020 in IJEAST (http://www.ijeast.com)}

\section{METHODOLOGY}

\section{A. Theoretical framework}

Any research develops its accuracy based on the initial theoretical calculations that have been done. The theoretical calculations that has been carried out in our research has certain assumptions and fixing a few values based on the design of the pintle injector. The formulas that has been mentioned below are obtained from the journal paper Min Son, et al . [2017] and the same has been used to calculate the TMR, SMD, Spray angle for two different angles at two throttling ranges.

$$
\begin{gathered}
\text { Lopen } \max =\frac{R \text { post }-\sqrt{R \text { Rost }{ }^{2}-A \operatorname{cg} * \frac{\sin \theta}{\pi}}}{\sin \theta * \cos \theta} \\
m o \cdot=\rho * A o * v . \\
W e=\frac{\rho * \Delta v^{2} * \text { Lopen }}{\mu} \\
S M D=\text { Lopen } * \varepsilon^{-1} * e^{4-q * W e^{0.1}} \\
T M R=\frac{(m \cdot V) o * \cos \theta}{(m \cdot V) o * \sin \theta+(m \cdot V) f} \\
\alpha=\cos ^{-1}\left(\frac{1}{1+T M R}\right)
\end{gathered}
$$

\section{B. Theoretical results}

\section{CASE - 1}

For $\mathbf{2 0}^{\circ}$ pintle angle, the throttling conditions are $100 \%$ and $60 \%$. The variations in all the parameters are shown in the below table. The assumptions made according to the design of the injector which is mentioned below in the methodology are Rpost $=6 \mathrm{~mm}$.; Rcg $=5.5 \mathrm{~mm}$

Lopen $=0.5$ for $100 \%$ throttling and 0.3 for $60 \%$ throttling Density of oxidizer $=1141 \mathrm{~kg} / \mathrm{m}^{3}$;

Density of fuel $=789 \mathrm{~kg} / \mathrm{m}^{3}$

\section{CASE - 2}

For $3^{\circ}$ pintle angle, the throttling conditions are $100 \%$ and $60 \%$. The variations in all the parameters are shown in the below table. The assumptions made for the second case are similar to the first one except the pintle angle.

Table -1 Results for $22^{\circ}$ angle with $100 \%$ (0.5) and 60\% (0.3) throttling

\begin{tabular}{|c|c|c|}
\hline PARAMETERS & $\mathbf{0 . 5 m m}$ & $\mathbf{0 . 3 m m}$ \\
\hline Lopen max & $2.91 \mathrm{E}-03$ & $2.91 \mathrm{E}-03$ \\
\hline Lopen $(\mathbf{m m})$ & 0.5 & 0.3 \\
\hline Rpost $(\mathbf{m m})$ & 6 & 6 \\
\hline Rcg $(\mathbf{m m})$ & 5.5 & 5.5 \\
\hline Ao $\left(\mathbf{m}^{\mathbf{2}}\right)$ & $1.75 \mathrm{E}-05$ & $1.05 \mathrm{E}-05$ \\
\hline $\mathbf{m}(\mathbf{d o t}) \mathbf{o x}(\mathbf{g} / \mathbf{s})$ & 280.15 & 244.47 \\
\hline $\mathbf{m}(\mathbf{d o t}) \mathbf{f u e l}(\mathbf{g} / \mathbf{s})$ & 200.11 & 174.62 \\
\hline
\end{tabular}

\begin{tabular}{|c|c|c|}
\hline m (dot) total (g/s) & 480.26 & 419.09 \\
\hline $\begin{array}{c}\text { Surface tension } \\
\text { (dynes/cm) }\end{array}$ & 1.11 & 1.11 \\
\hline V ox (m/s) & 14.05 & 20.324 \\
\hline V fuel (m/s) & 24.23 & 24.84 \\
\hline Delta V (m/s) & 10.18 & 4.52 \\
\hline We & 36831.51 & 4356.64 \\
\hline SMD (microns) & $2.95 \mathrm{E}-06$ & $1.08 \mathrm{E}-05$ \\
\hline TMR & 0.59 & 0.77 \\
\hline Re ox & 154531.03 & 134121.94 \\
\hline Re fuel & 8384.85 & 8595.94 \\
\hline Oh & $1.24 \mathrm{E}-03$ & $4.92 \mathrm{E}-04$ \\
\hline Spray angle (deg) & 51.02 & 55.59 \\
\hline
\end{tabular}

Table - 2 Results for $33^{\circ}$ angle with $100 \%(0.5)$ and $60 \%$ (0.3) throttling

\begin{tabular}{|c|c|c|}
\hline PARAMETERS & $\mathbf{0 . 5 m m}$ & $\mathbf{0 . 3 m m}$ \\
\hline Lopen max & $3.46 \mathrm{E}-03$ & $3.46 \mathrm{E}-03$ \\
\hline Lopen (mm) & 0.5 & 0.3 \\
\hline Rpost (mm) & 6 & 6 \\
\hline Rcg (mm) & 5.5 & 5.5 \\
\hline Ao (m) $\mathbf{m}^{\mathbf{})}$ & $1.55 \mathrm{E}-05$ & $9.37 \mathrm{E}-06$ \\
\hline m (dot) ox (g/s) & 250.72 & 223.5 \\
\hline m (dot) fuel (g/s) & 179.08 & 159.64 \\
\hline m (dot) total (g/s) & 429.8 & 383.14 \\
\hline Surface tension & 1.11 & 1.11 \\
(dynes/cm) & & \\
\hline V ox (m/s) & 14.17 & 20.89 \\
\hline V fuel (m/s) & 24.12 & 24.38 \\
\hline Delta V (m/s) & 9.95 & 3.49 \\
\hline We & 35186.02 & 2597.32 \\
\hline SMD (microns) & $3.44 \mathrm{E}-06$ & $1.80 \mathrm{E}-05$ \\
\hline TMR & 0.475 & 0.6 \\
\hline Re ox & 155850.88 & 1373857.09 \\
\hline Re fuel & 8346.79 & 8436.76 \\
\hline Oh & $1.20 \mathrm{E}-03$ & $3.70 \mathrm{E}-04$ \\
\hline Spray angle (deg) & 47.31 & 51.31 \\
\hline
\end{tabular}

\section{Analysis methodology}

The design of the pintle injector has been done on CFD with commercial ANSYS fluent R 17.0 in the design modular with the following dimensions. Mesh independent study was done using various meshes on the face split geometry. Before we moved on to the mesh independent study, we first created the all quadrilateral mesh. Mesh independent study is said to be achieved when the solution does not vary when the mesh is further refined. Initially we start with coarse mesh and further refine it. This results in difference in solution as the mesh is improved further. As the mesh becomes finer, there exist a limit after which no changes in the solution is observed in the result even when it is further refined. When this saturation point is reached, it is said that we 
have achieved Mesh independence. This means that further refining the mesh would not result in the variation in solution and that the mesh has captured the most intricate details of the flow.

Table -3 Different mesh sizes for $20^{\circ}$ pintle angle

\begin{tabular}{|c|c|c|c|}
\hline No. of nodes & No. of elements & Vo & Vf \\
\hline 101307 & 100607 & 14.23 & 24.54 \\
\hline 1276626 & 126850 & 14 & 24.9 \\
\hline 222174 & 221178 & 14.5 & 24.23 \\
\hline
\end{tabular}

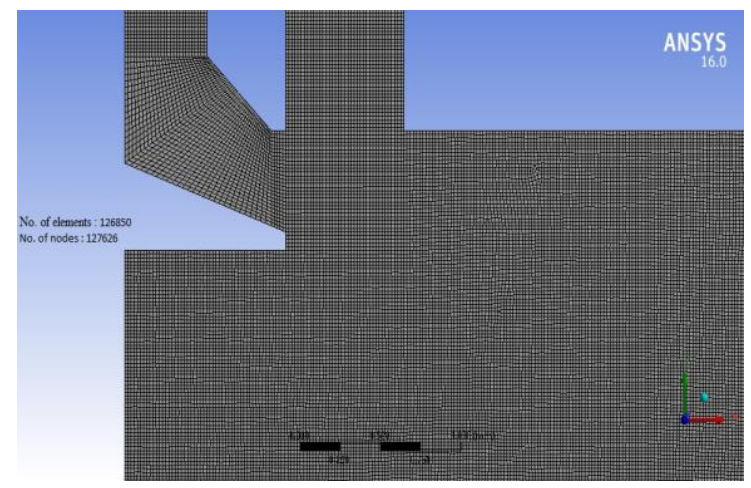

Fig. 2. Face split mesh done at region 1 for 0.5 Lopen

The similar kind of mesh study was obtained for the other 3 cases as well. Once the mesh study was conducted, we moved on to the analysis part which is described as CFD with commercial ANSYS Fluent R17.0 software is used for all simulations carried out in this project. Once the design has been created in the design modular and meshed, it is imported to the Fluent section where certain conditions which are pre-installed has been used to continue with the simulation process. We have considered multiphase flow model for our work. A multiphase flow is the one where more than one fluid flow simultaneously. In multiphase flow, a phase can be characterized as a recognizable class of material that has a specific inertial reaction to and interaction with the flow and the potential field in which it is submerged.

Multiphase flow can be grouped into the categories: Two phase flows and Three phases flows. The two-phase flows can be further divided into gas-liquid, liquid-liquid, gas-solid, liquid-solid flows. Our flow consists of primary phase and secondary phase. The primary phase being air and the secondary phases include Liquid oxygen and Ethyl-alcohol. In the Euler-Euler approach, the different phases are treated as interpenetrating continua. Volume-averages mass conservation equation is used for solving each phase and the concept of volume fraction is introduced. Three different Euler-Euler multiphase flow model are available in Ansys Fluent. This includes the Volume of Fluid model (VOF), Mixture model and Eulerian Model. VOF model is intended for at least two immiscible liquids. A single set of momentum equation is used to model two or more immiscible liquids. The volume fraction of each of the fluid is tracked throughout the domain. The following kind of flows were obtained for all 4 cases.

\section{CASE $1-20 \mathrm{deg}, 0.5 \mathrm{~mm}$}

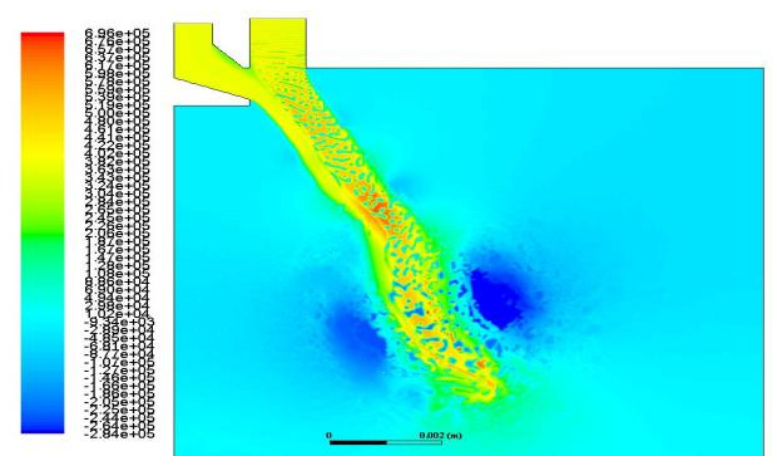

Fig. 3. Total pressure distribution

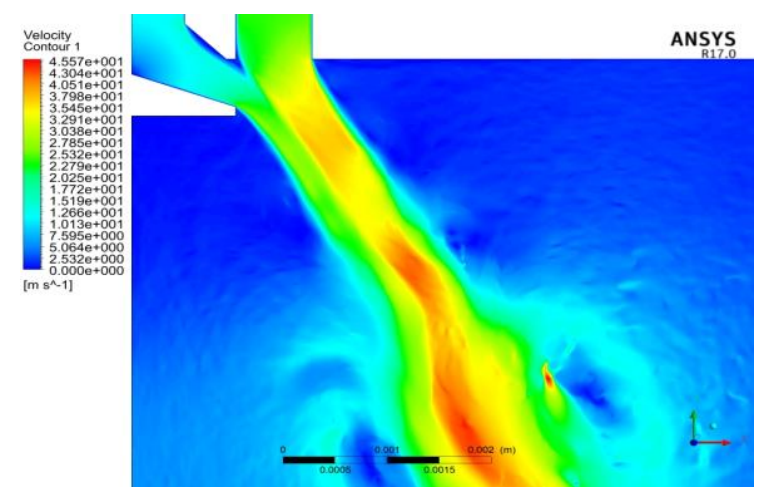

Fig. 4. Velocity contours

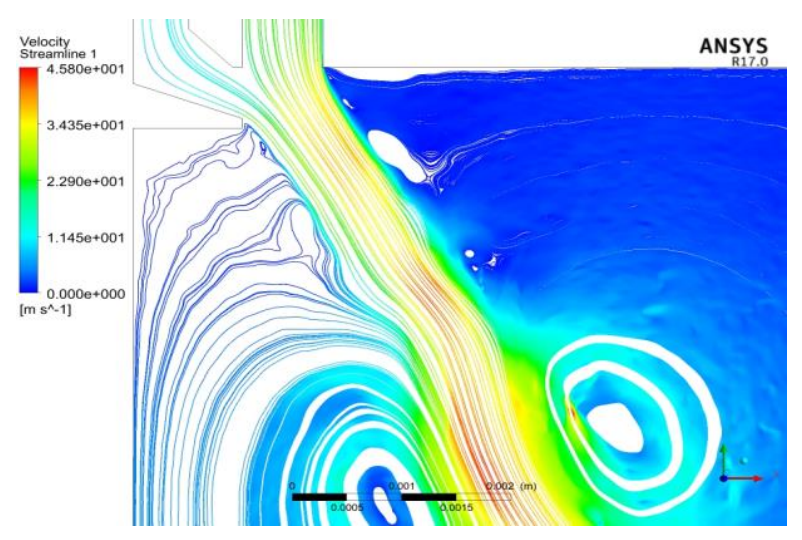

Fig. 5. Velocity streamline ( recirculation pattern ) 
Published Online May 2020 in IJEAST (http://www.ijeast.com)

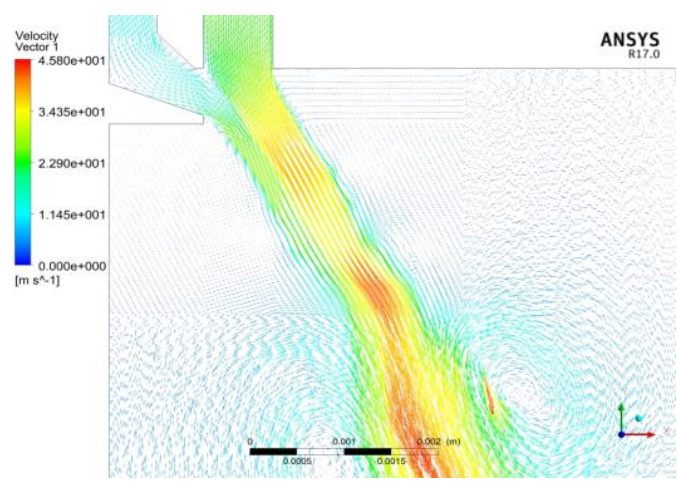

Fig. 6. Velocity vector

\section{CASE 3 - $33 \mathrm{deg}, 0.5 \mathrm{~mm}$}
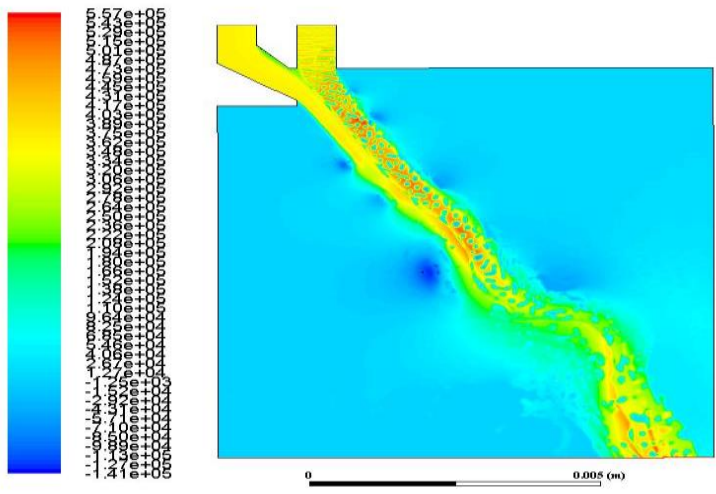

Fig. 7. Total pressure distribution
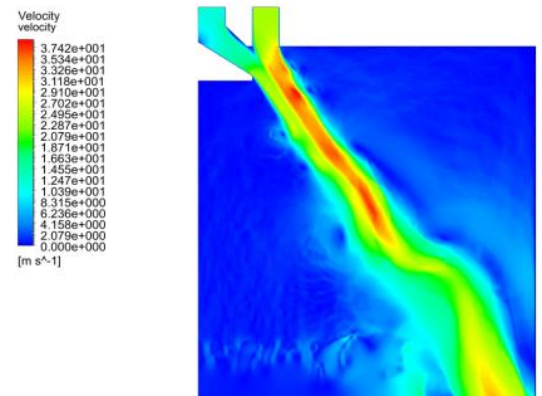

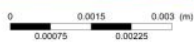

Fig. 8. Velocity contour
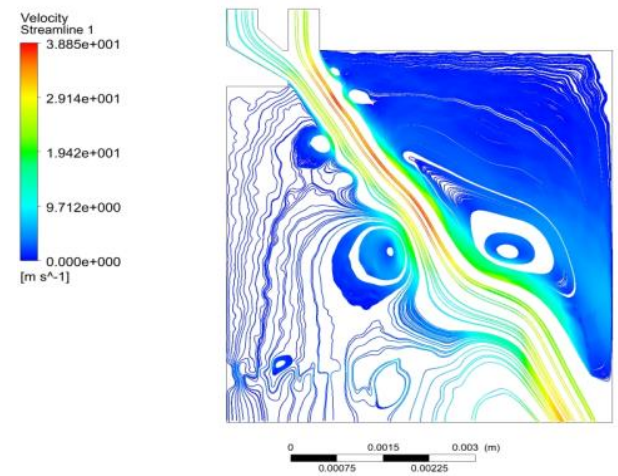

ANSYS

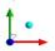

Fig. 9. Velocity streamline ( Recirculation pattern )
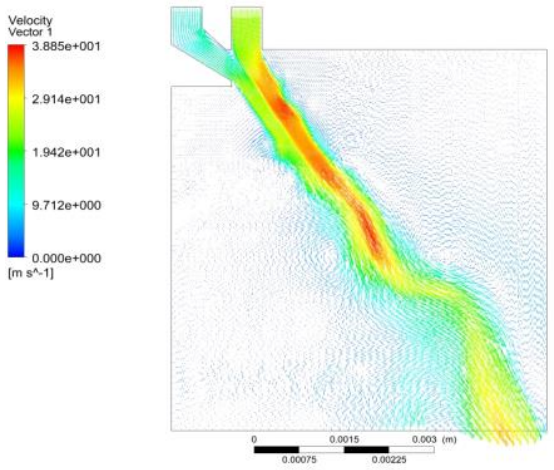

ANSYS

Fig. 10. Velocity vector

The analysis of $0.3 \mathrm{~mm}$ for both the angles yields similar results as the above tow cases using the same model and same comditiions .

\section{RESULTS AND DISCUSSIONS}

The results are divided into two different

The simulation results mainly comprise of

For $20^{\circ}$

Velocity contours

Velocity streamlines - recirculation

For $33^{\circ}$

Velocity contours

Velocity streamlines - recirculation

The graphs that show the point of convergence after a certain time step and the residual graph with respect to the number of iterations. The graphs give us the relation between the parameters and how they behave with one another for a given condition in a pintle injector.

$20^{\circ}$ velocity contours 
International Journal of Engineering Applied Sciences and Technology, 2020 Vol. 5, Issue 1, ISSN No. 2455-2143, Pages 151-159

Published Online May 2020 in IJEAST (http://www.ijeast.com)
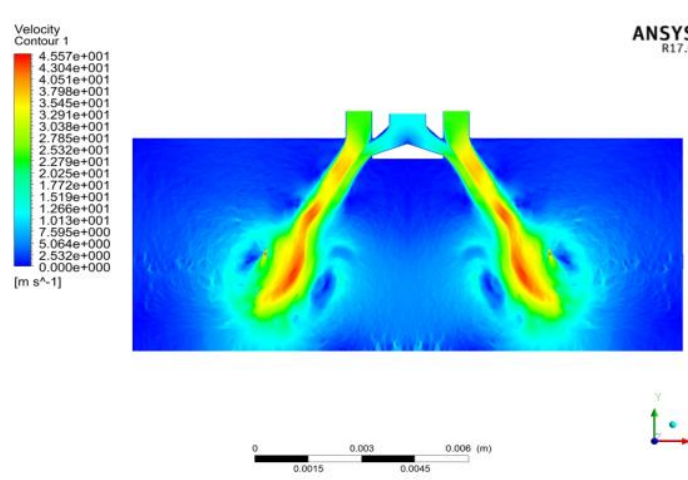

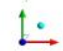
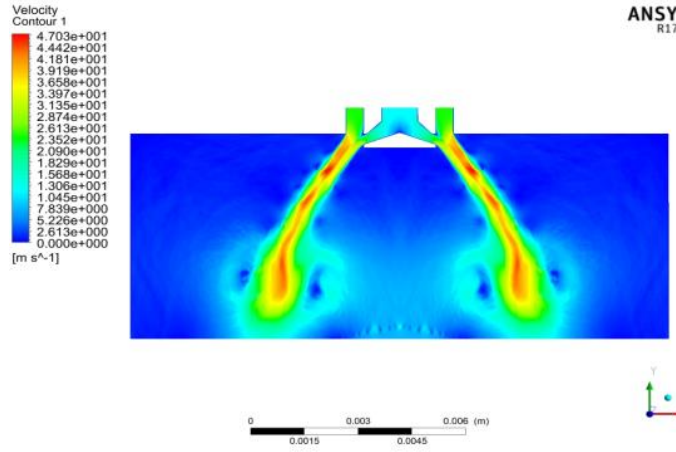

Fig. 11. (a) velocity vector for 0.5 and $0.3 \mathrm{~mm}$

$20^{\circ}$ velocity streamline - recirculation
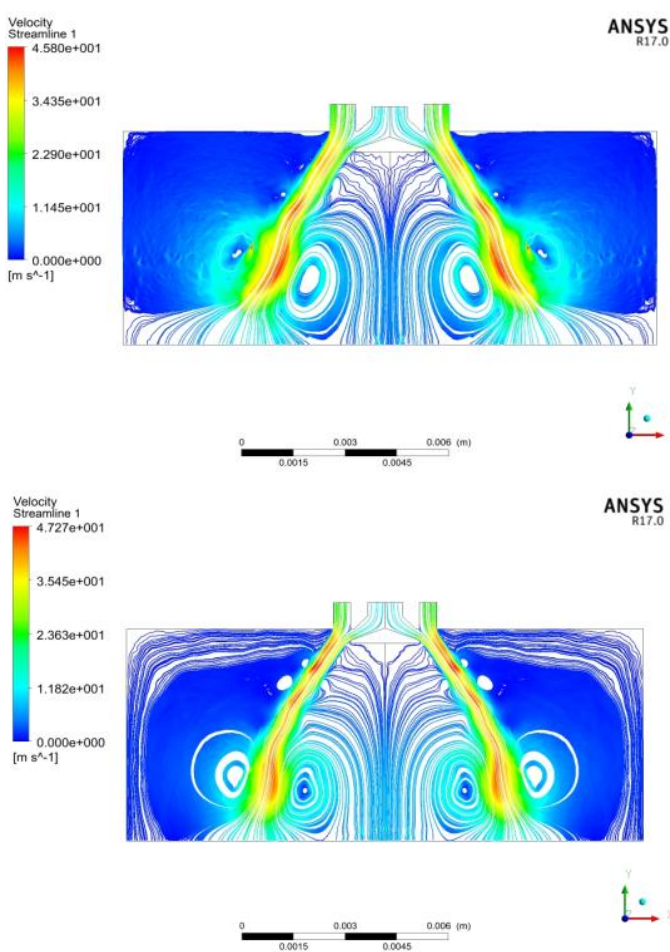

$\stackrel{\leftrightarrow}{\longrightarrow}$
Fig. 12. (b) velocity streamline for 0.5 and $0.3 \mathrm{~mm}$

$33^{\circ}$ velocity contours
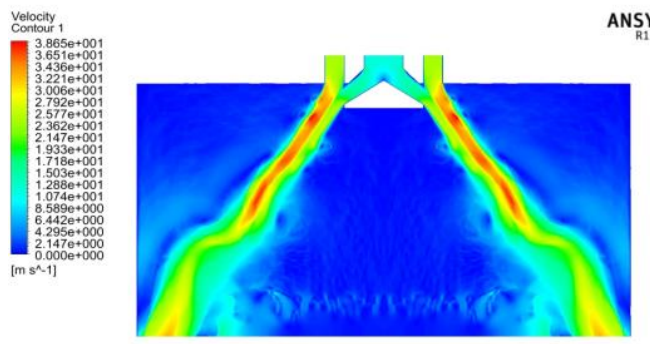

ANSYS
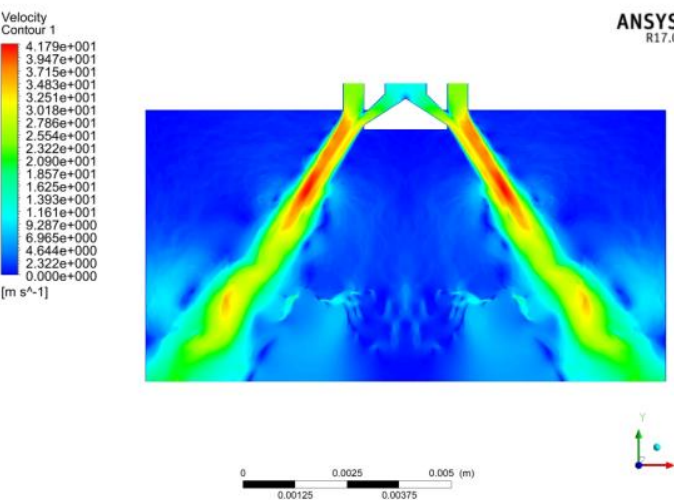

$\stackrel{\leftrightarrow}{\longleftrightarrow}$

Fig. 13. (a) velocity vector for 0.5 and $0.3 \mathrm{~mm}$

$3^{\circ}$ velocity streamline - recirculation

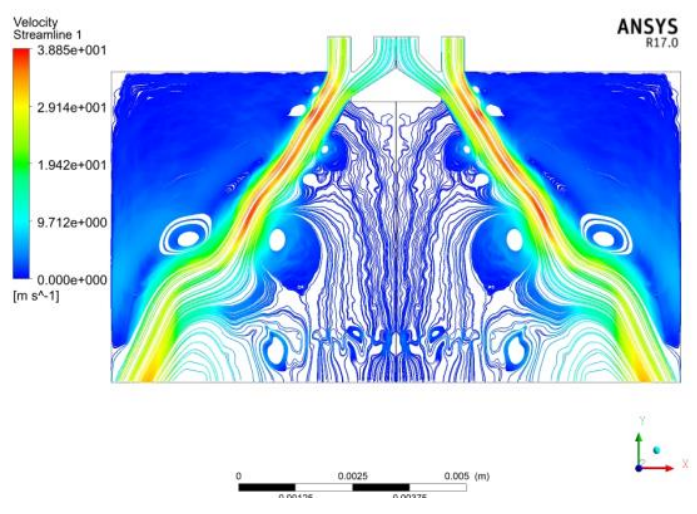


International Journal of Engineering Applied Sciences and Technology, 2020

Vol. 5, Issue 1, ISSN No. 2455-2143, Pages 151-159

Published Online May 2020 in IJEAST (http://www.ijeast.com)
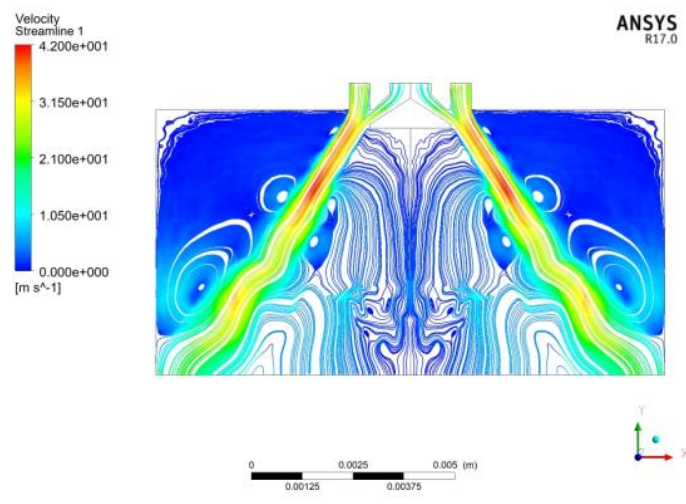

Fig. 14. (b) velocity streamline for 0.5 and $0.3 \mathrm{~mm}$

\section{DISCUSSION}

The 33-degree pintle angled injectors show a stable flow when compared to the 20-degree pintle angle. The recirculation when highlighted, the recirculation zones are much further away from the pintle head and this prevents interaction of the unburnt droplets with that of the incoming stream . But in this case there are high chances of the droplets passing out of the nozzle unburnt .This hampers the combustion efficiency to certain extent as compared to that of the $20 \mathrm{deg}$ pintle angle . But it is very safe to infer that the 33 degree pintle angles are very less prone to combustion instability than the 20 degree pintle angle injectors. The mass flow rates are less compared to that of the 20 degree pintle angle . 33 degree pintle angle has an upper hand in the throttling range and maximum thrust generated. The Lopen,max range limit is high compared to that of the 20 degree. SMD values obtained by the 33 degree pintle angle are quite high when compared to that of the 20 degree. The problem with the use of a 20 degree pintle angle is that it has the recirculation zone approaching very close to that of the pintle head. The SMD values are lower for 20 degree than the 33 degree pintle angle which is a good sign. But the fact that the unburnt particles are in close proximity of the incoming stream makes the particles drift out of the flow reaching to the hotspots, releasing the energy at other antinodes. This surely initiates a combustion instability. With increase in the Lopen, there is an increase in the momentum and hence the relative velocity. This means that there are very less droplets that miss out on undergoing the process of combustion at higher throttling levels. This can also suggest that when the motors are throttled, they have to prevent lower level throttling as much as possible. The combination of lower pintle angles and lower throttling ranges are to be prevented, at least considering the case of combustion instability. The TMR values are also influenced by the Lopen. A narrow Lopen is successful in generating higher TMR than the higher Lopen. The Ohnesorge number and the Weber number is high in the case of 20 degrees. This indicates a very fine spray. The Ohnesorge number and the Weber number is high for higher Lopen . Therefore to have a finer spray the conditions to be followed are lower pintle angle and higher Lopen values. The below graphs are the residual and convergence graphs which are same for all cases as the graphs converged for every time step.

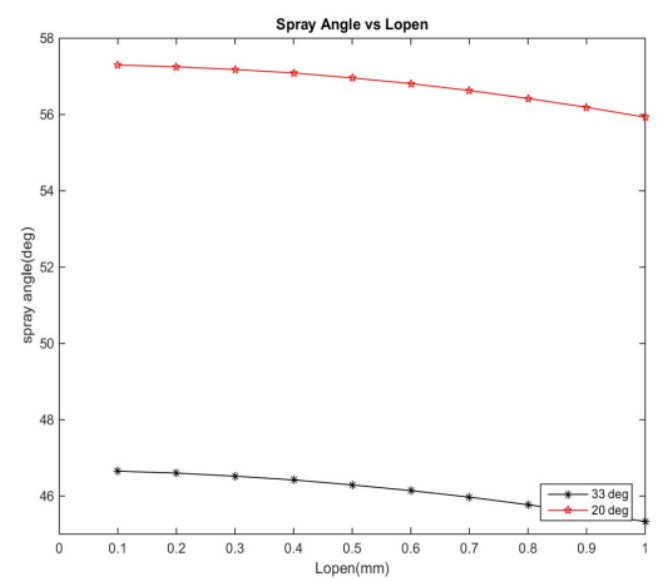

Fig. 15. Lopen (mm) vs Spray angle (deg)

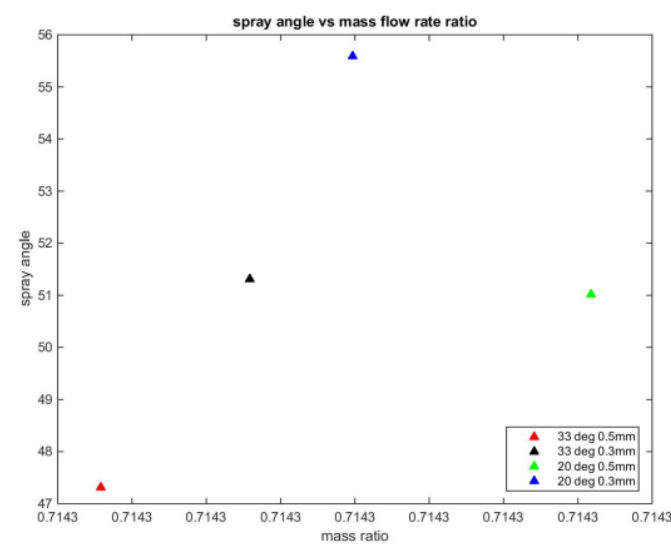

Fig. 16. Mass ratio vs Spray angle

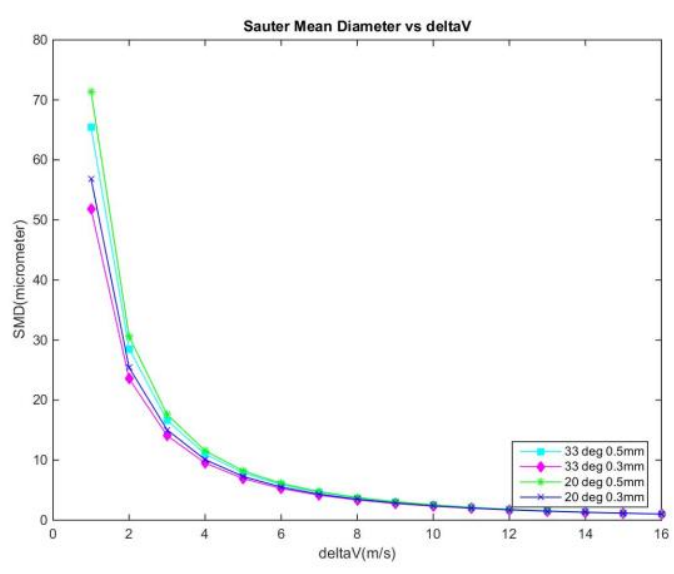

Fig. 17. Delta V vs SMD 


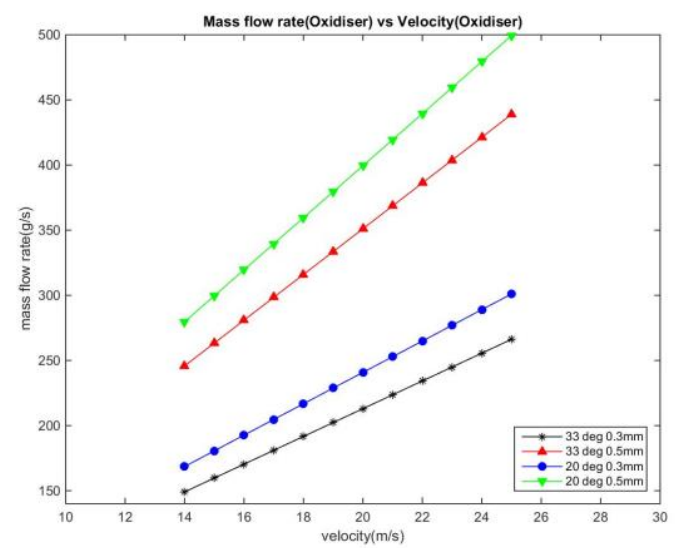

Fig. 18. Velocity vs mass flow rate

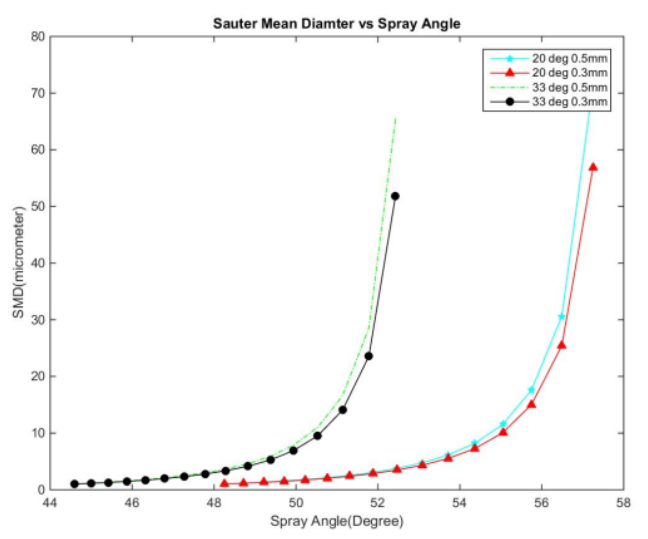

Fig. 19. Spray angle vs SMD

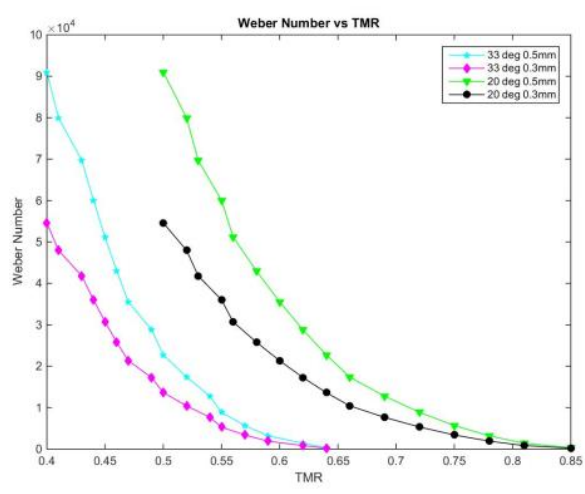

Fig. 20. TMR vs Weber number

\section{CONCLUSION}

In this study, the former designs and design methods of a pintle injector are thoroughly studied. A compact design for LOX and Ethanol liquid rocket engine is presented in terms of geometrical constraints. One design with two different pintle angles are designed in order to be tested. With the help of the literature review, non-dimensional parameters are used to represent the hot flow design conditions. Liquid oxygen and ethanol are used as simulants of the real propellants. The spray angle and Sauter mean diameter (SMD) were chosen as the significant parameters for this research project. We studied the variation in TMRs for different spray angles and mass flow rates. This helps in improving the performance of the engine during throttling. This abstain from combustion instability due to proper curved surface combustion zone of the spray due to the TMR. Hence preventing failure of the mission.

\section{ACKNOLEDGEMENT}

We would like to thank our guide Dr. R Rajendran, Prof Sudarshan Kumar (IITB), Prof Srinivasan (RVCE) and Mr. Omkar (IITB) for their constant support and encouragement. A sincere gratitude to Prof. Mayur Anvekar who suggested this particular journal to us. We would also like to thank the authors of the papers we have referred as that laid the foundation to our whole project. We would like to thank our family and friends for their valuable inputs and suggestions in due course of completing this paper.

\section{REFERENCE}

[1] Son Min,* Radhakrishnan Kanmaniraja, $\uparrow$ Koo Jaye, Oh Chae Kwon, Heuy Dong Kim , July-August 2017 "Design Procedure of a Movable Pintle Injector for Liquid Rocket Engines" JOURNAL OF PROPULSION AND POWER Vol. 33, No. 4, DOI: 10.2514/1.B36301.

[2] Son Min, Yu Kijeong, Koo Jaye, Oh Chae Kwon, Jeong Soo Kim, (2015), "Effects of Momentum Ratio and Weber Number on Spray Half Angles of Liquid Controlled Pintle Injector", Journal of Thermal Science Vol.24, No.1 37-43, 2015 DOI: 10.1007/s11630-015-0753-7.

[3] Son Min, Kijeong Yu, Radhakrishnan Kanmaniraja, Shin Bongchul and Koo Jaye , (2016) "Verification on Spray Simulation of a Pintle Injector for Liquid Rocket Engine", Journal of Thermal Science Vol.25, No.1 90-96, 2016 DOI: 10.1007/s11630-016-0838.

[4] Son Min, Radhakrishnana Kanmaniraja, Yoonb Youngbin, Jaye Kooc, (2017), "Numerical study on the combustion characteristics of a fuel-centered pintle injector for methane rocket engines"

Son,M.,ActaAstronautica http://dx.doi.org/10.1016/j.actaastro.2017.02.005

[5] Berksu Erka. "Design of a pintle injector" a thesis.

[6] Dressler Gordon A. and Bauer J. Martin, "TRW Pintle Engine Heritage and Performance Characteristics," AIAA Paper 2000-3871, 200 
[7] Gromski Jason M., Majamaki Annik N., Silvio G., and Chianese Vladimir D. Weinstock, 2010 , "Northrop Grumman TR202 LOX/LH2 Deep Throttling Engine Technology Project Status ”, AIAA 2010-6725,

[8] Sakaki Kazuki, Kakudo Hiromitsu, Nakaya Shinji, Mitsuhiro Tsue, Suzuki Kyohei, Ryuichiro Kanai Takahiro Inagaw, Tetsuo Hiraiwa , 2016 "Combustion Characteristics of Ethanol/Liquid-Oxygen Rocket-Engine Combustor with Planar Pintle Injector", DOI: 10.2514/1.B36144

[9] A Historical Systems Study of Liquid Rocket Engine Throttling Capabilities Erin M. Betts*National Aeronautics and Space Administration, Huntsville, AL, 35812 and Dr. Robert A. Frederick, Jr. University of Alabama in Huntsville, Huntsville, AL, 35899

[10] Cheng Peng, Li Qinglian, Shun Xu c, Kang Zhongtao “The prediction of spray angle of liquid-liquid pintle injectors"., Acta Astronautica, Volume 138, p. 145-151, September 2017, 10.1016/j.actaastro.2017.05.037.

[11] Modern engineering for design for liquid propellant rocket engines by Dieter K. Huzel and David H. Huang.

[12] Study on atomization and combustion characteristics of LOX/methane pintle injectors Xin-xin FangChi-bing Shen Volume 136,

July 2017. DOI : 10.1016/j.actaastro.2017.03.02 